NASA Technical Memorandum 105348

IAF-91-254

\title{
High Temperature Thruster Technology for Spacecraft Propulsion
}

Steven J. Schneider

Lewis Research Center

Cleveland, Ohio

Prepared for the

42nd Congress of the International Astronautical Federation

Montreal, Canada, October 5-11, 1991 
High Temperature Thruster Technology for Spacecraft Propulsion

\author{
Steven J. Schneider \\ NASA Lewis Research Center \\ $\mathrm{Cleveland,} \mathrm{OH} \quad 44135$
}

Abstract

A technology program has been underway since 1985 to develop high temperature oxidation-resistant thrusters for spacecraft applications. The successful development of this technology will provide the basis for the design of higher performance satellite engines with reduced plume contamination. Alternatively, this technology program will provide a material with high thermal margin to operate at conventional temperatures and provide increased life for refuelable or reusable spacecraft. The new chamber material consists of a rhenium substrate coated with iridium for oxidation protection. This material increases the operating temperature of thrusters to $2200^{\circ} \mathrm{C}$, a significant increase over the $1400^{\circ} \mathrm{C}$ of the silicide-coated niobium chambers currently used. Stationkeeping class $22 \mathrm{~N}$ engines fabricated from iridium-coated rhenium have demonstrated steady state specific impulses 20 to 25 seconds higher than niobium chambers. Ir-Re apogee class $440 \mathrm{~N}$ engines are expected to deliver an additional 10 to 15 seconds. These improved performances are obtained by reducing or eliminating the fuel film cooling requirements in the combustion chamber while operating at the same overall mixture ratio as conventional engines. The program is attempting to envelope flight qualification requirements to reduce the potential risks and costs of flight qualification programs.

\title{
Introduction
}

The development of rockets suitable for spacecraft propulsion traditionally was accomplished with project support. For example, projects such as Apollo and Space Shuttle flight qualified $110 \mathrm{~N}^{1}, 440 \mathrm{~N}^{2}$ and variable thrust 4400 to 44000 $\mathrm{N}^{3}$ rockets. However, due to project time and resource constraints, improvements to low thrust rockets were incremental. Currently, a NASA-OAET supported program ${ }^{4,5}$ is on-going to provide technology for a broad class of applications. Multimission flight qualification requirements are to be enveloped. Projects are then expected to develop the technology into flight qual ified hardware for NASA, Department of Defense, or commercial missions. Typical applications for low thrust rocket technology include launch vehicle reaction control, attitude control and positioning of Low Earth Orbit (LEO) satellites, apogee and N-S stationkeeping for geosynchronous satellites, and planetary "delta V" and retropropulsion. The conventional material used for low thrust bipropellant rockets consists of a niobium alloy $(C-103)$ coated with a disilicide material for oxidation protection. The coating is applied as a slurry and vacuum fused to the niobium alloy and is in widespread use. Chamber life is determined by an oxidation process called "pesting" in which thermal cycling and/or time at temperature causes crack growth in the coating and eventual oxidation of the niobium. The dependence of 1 ife versus operating temperature ${ }^{6}$ for this material is given in Figure 1, which shows an order of magnitude decrease in life for each $150^{8} \mathrm{C}$ increase in operating temperature. For example, a life of 10 hours is expected when operating at $1400^{\circ} \mathrm{C}$. Generally, a performance-life trade-off is 
conducted in a development program to meet mission requirements where higher performance is obtained at higher operating temperatures.

The current NASA-OAET program led to the introduction of a new material system into low thrust rocket technology. This material system consists of a rhenium substrate coated with iridium for oxidation protection. This paper will discuss the technology program ${ }^{4}$ that led to this material, review the design and fabrication of rockets with these materials, and present recent test results with rockets using these materials.

\section{Materials}

The technology program ${ }^{4}$ under which candidate materials were screened for $2200^{\circ}$ $C$ thruster operation focused on materials consisting of substrates with oxidation resistant coatings. No monolithic materials were found capable of surviving a rocket engine environment. Refractory metals, ceramics, ceramic composites, and carbon-carbon were considered for substrates. Platinum group metals and alloys, Engle-Brewer compounds, ceramics, and silicides were considered for coatings. Selection criteria were established for both substrates and coatings in order to screen the potential materials. These criteria were melting point $\left(3130^{\circ} \mathrm{C}\right)$, oxidation resistance, coefficient of thermal expansion, strength, thermal shock resistance, fabricability and adherence. Based on these criteria, rhenium (Re) was selected as the substrate material due to its high melting point, excellent strength at high temperature, absence of a ductile-to-brittle transition temperature, and fabricability by Chemical Vapor Deposition ${ }^{7}$ (CVD). CVD is a method of plating which relies on the chemical reaction of a vapor at a surface to form solid structural deposits. A schematic of a CVD apparatus for Re is shown in Figure 2. Chlorine gas is fed into a chamber containing rhenium metal which is heated to about $500^{\circ} \mathrm{C}$. Rhenium pentacholoride ( $\left(\mathrm{ReCl} \mathrm{T}_{5}\right.$ ) is formed and then passes over a net shape preform mandrel heated to $1200^{\circ} \mathrm{C}$ by an induction coi1. At the hot mandrel surface, the $\mathrm{ReCl}_{5}$ decomposes, the Re metal deposits on the mandrel, and chlorine gas passes out the exhaust. When the $\operatorname{Re}$ is sufficiently thick, the mandrel is chemically removed and a free-standing structure is obtained. Iridium (Ir) was chosen as the oxidation resistant coating for rhenium because of its adequate melting temperature $(2450 \mathrm{C})$, good oxidation resistance ( 3 orders of magnitude better than $\mathrm{Re}$ ), close coefficient of thermal expansion to rhenium, ductility, and fabricability into an adherent coating on rhenium by a CVD process. ${ }^{7}$ The CVD procedure for depositing iridium is shown schematically in Figure 3. The precursor compound of iridium is known as iridium acetylacetonate (Ir ac-ac) with the structural formula Ir $\left(\mathrm{CH}_{3} \mathrm{COCHCOCH}_{3}\right)_{3}$. The Ir ac-ac is heated to a sublimation temperature and the Ir ac-ac vapor is swept by carrier/reaction gases past a heated mandrel on which iridium deposits while the reaction products are exhausted. The precise details of this process are proprietary, since they were developed on a Small Business Innovative Research Program with NASA. A schematic of the thruster fabrication process is shown in Figure 4. First, the net shape of the inside surface of the thrust chamber is machined onto a molybdenum mandrel. Second, the iridium coating, typically 50 microns thick, is deposited on the mandrel. Third, the rhenium, typically 1000 microns thick, is deposited onto the Ir coated mandrel. Fourth, the mandrel is chemically removed, leaving a free standing thrust chamber.

The Ir coated Re material system is projected to fail by diffusion of the rhenium through the iridium followed by its subsequent oxidation and removal at the 
iridium surface. Thermogravimetric analyses ${ }^{4}$ (TGA) were used to measure the oxidation rates of $\mathrm{Ir}$ and Ir-Re alloys. The environment in the TGA was chosen as $\mathrm{H}_{2} \mathrm{O}$ saturated $\mathrm{Ar}+0.5 \% \mathrm{O}_{2}$ at a pressure of $190 \mathrm{~Pa}$ to simulate the approximate $\mathrm{O}_{2}$ content near the thrust chamber wall during steady state operation of a rocket with a non-streaking injector. A typical TGA temperature profile consisted of a temperature rise of $5^{\circ} \mathrm{C} /$ minute to $1540^{\circ} \mathrm{C}$, isothermal hold at $1540^{\circ} \mathrm{C}$ for two hours, followed by cooling. Mass loss rates for pure Ir, Ir $+20 \% \mathrm{Re}$, and $\mathrm{Ir}+$ $40 \%$ are shown in Figure 5 . These convert into material recession rates of 0.15 , 0.36 , and 58.1 microns/hour for $\mathrm{Ir}$, IR $+20 \% \operatorname{Re}$, and $\mathrm{Ir}+40 \% \mathrm{Re}$, respectively. Also shown in Figure 5 are TGA mass loss results for the materials in an environment of $\mathrm{H}_{2} \mathrm{O}$ saturated $\mathrm{N}_{2}+67 \% \mathrm{O}_{2}$ at a pressure of $190 \mathrm{~Pa}$. These convert to material recession rates of 0.86 and 2.43 microns/hour for Ir and Ir $+20 \% \operatorname{Re}$, respectively. Ir $+40 \%$ Re was not done because of the rapid oxidation at $0.5 \%$ $\mathrm{O}_{2}$ in the previous tests. Oxygen partial pressure near the surface was therefore predicted to have a significant effect on life, indicating the need for nonstreaking injector designs.

The interdiffusion of iridium and rhenium was also investigated. ${ }^{8}$ The morphology (ie. grain size and structure) of the sample was expected to affect diffusion rates, therefore samples were prepared by the CVD process. Couples were vacuum annealed at up to $1900^{\circ} \mathrm{C}$ for 8 hours. No significant grain growth occurred during the annealing process. The average grain size of Ir was 10 um and the average grain size of the Re was 400 um. Electron microprobe analyses were used to determine the distribution of $\mathrm{Re}$ and $\mathrm{Ir}$. A typical electron microprobe analysis of a cross-section of an iridium-rhenium specimen is shown in Figure 6. Significant diffusion of Re along Ir grain boundaries was found, as shown by the mottled pattern in Figure 6 . A line scan of percent iridium perpendicular to the Ir-Re interface in Figure 6 is shown in Figure 7 . Little diffusion of Ir into the Re was observed as shown by the discontinuity in slope of the data at 52 microns depth. The data in this figure were then used to curve fit the diffusion equation for diffusion of rhenium into a semi-infinite medium of iridium where the boundary is held at a constant concentration, $C_{0}$. This equation is given in Reference 7:

$$
C=C_{0} \operatorname{erfc}[(x-h) /(2 \sqrt{D t}]
$$

where $C$ is concentration of rhenium as a function of time and distance, $C_{0}=100$, $h$ is the thickness of the Ir coating on the Re, $t$ is time, and $x$ is the distance from the surface of the iridium into the material. The diffusion constant $D$ is the parameter of the curve fit. The curve fit shown in Figure 7 yields $D=$ $4.7 \times 10^{-11} \mathrm{~cm}^{2} / \mathrm{sec}$ at $1900^{\circ} \mathrm{C}$. (Note that iridium concentration, ie, 100-C is plotted in Figure 7). Other samples were also vacuum annealed at $1400^{\circ} \mathrm{C}$ and $1700^{\circ} \mathrm{C}$ and their diffusion constants were measured. These diffusion constants are plotted in Figure 8 as a function of inverse temperature and are found to have an Arrhenius dependence. They can be fit to an equation of the form:

$$
D=D_{0} \exp (-E / k T)
$$


where $D_{0}=3.14 \times 10^{-8} \mathrm{~cm}^{2} / \mathrm{sec}$ and $E / \mathrm{K}=1.42 \times 10^{4} \mathrm{~K}$. The model for diffusion constant is extrapolated to an operating temperature of $2200^{\circ} \mathrm{C}$ to yield $\mathrm{D}=$ $1.01 \times 10^{-10} \mathrm{~cm}^{2} / \mathrm{sec}$.

Concurrent with these fundamental material analyses, direct characterization of this material combination in a rocket engine environment was conducted. Small $22 \mathrm{~N}$ iridium-lined rhenium thrust chambers were fabricated with 50 microns of iridium on 1000 microns of rhenium by the CVD process. Testing was performed with MMH/NTO propellants in an altitude test cell to avoid oxidation of the Re in the atmosphere surrounding the rocket. This material demonstrator chamber was attached to a water-cooled injector and was tested at a mixture ratio (MR) of 1.65. The equilibrium chamber temperature achieved was $2200^{\circ} \mathrm{C}$ and a firing time of 17 hours was demonstrated without failure. Inspection revealed the chamber to be in good condition. Initial chamber and throat diameter measurements were 8.979 to $11.201 \mathrm{~mm}$ and 4.280 to $4.293 \mathrm{~mm}$ respectively. Post test measurements of the chamber diameter were found to be unchanged, i.e., the measurement accuracy did not permit a recession measurement. Throat diameter was measured and was found to be 4.293 to $4.305 \mathrm{~mm}$, i.e., about 13 microns 1arger. A material recession rate of 0.42 microns/hour at $2200^{\circ} \mathrm{C}$ was projected based on this test.

A first order life prediction model based on this data was developed. The life limit in this model was set at the time for Re to diffuse through Ir and reach a $20 \%$ concentration at the surface while the surface is receding at a fixed recession rate. The life model then has functional dependence on operating temperature, Ir thickness, and surface recession rate. A life prediction at $2200^{\circ} \mathrm{C}$ is shown in Figure 9. The curve appears to be conservative since it predicts failure at around 16 hours for a coating of 50 microns of iridium while a chamber has been run at this temperature for 17 hours without any sign of failure. This conservatism, in part, is due to the fact that the diffusion data was generated with a constant temperature profile across the Ir-Re interface. In reality, there was a temperature profile due to radiation heat transfer, which reduced the Re temperature and therefore its diffusion rate. Using this 1 ife prediction mode1, chamber life is projected to increase to 50 hours with an Ir coating of 100 microns. A large uncertainty in life can result if a streaking injector produces a higher oxygen partial pressure near the surface as shown by the recession rate variation with oxygen concentration in Figure 5 . An alternative 1 ife prediction is also shown in Figure 9 for this material if it is used at a more conventional temperature of $1540^{\circ} \mathrm{C}$ to provide high thermal margin and increased life for refuelable or reusable spacecraft. For example, there was an expression of interest in a rocket material that would operate for 170 hours at $1000^{\circ} \mathrm{C}$ in Reference 8 for the Space Transportation System (STS) Orbiter vernier engines. Lifetimes of this magnitude are predicted to be feasible with 100 microns thick Ir coatings operating at $1400^{\circ} \mathrm{C}$. Efforts are underway to further enhance the oxidation/diffusion characteristics of the Ir-Re material system.

\section{Design and Fabrication of Rockets}

The design and fabrication of rockets using these materials for the rocket chamber requires a materials property data base and metallurgical joining technology. Much of the basic work on the properties of refractory materials was done in the 1960's and 1970's. However, the fabrication technologies at the time limited the applications of the materials. A review of this properties data base was given in Reference 4 . The grain structure of the tested materials, however, 
was different than that of CVD materials. The effect of this grain structure remains to be determined, but practical rocket designs have been demonstrated ${ }^{9}$ with the available materials property data. Metallurgical joining techniques to attach rhenium to dissimilar metals were also evaluated in Reference 3. Techniques such as inertia welding, furnace brazing, and electron beam (EB) welding were evaluated to join both wrought and CVD rhenium to Type 304L stainless steel, Hastelloy B2, and unalloyed niobium. Joints with titanium were not investigated. The inertia welding process successfully joined rhenium to niobium, however, joints with Type 304L stainless steel or Hastelloy B2 failed. Furnace brazing produced strong joints with all three materials investigated. Palcusil 25 and Nioro (BAU-4) braze filler metals were chosen based on their wetting ability on the four metals under investigation. The EB welding technique produced welds which were not true welds due to the great difference in melting temperature between rhenium and the other materials. These welds were more accurately described as a "parent metal braze". Ring shear specimens were then fabricated by these techniques. The fracture shear stress of these joints are given in Figure 10, showing that practical joints are possible by any of the techniques evaluated.

Two major design issues arise from the use of these materials for rocket chambers. They are: a) thermal management of the injector-chamber interface to avoid overheating the injector and b) providing adequate fatigue strength at the throat or head end to accommodate stresses which arise when these heavy metal chambers are cantilevered from the injector and undergo vibration during launch.

Thermal management of the injector-chamber can be accomplished via the use of fuel film coolant or mixture ratio control near the chamber wall along with increased thermal resistance or a regeneratively cooled section between the injector and chamber. Practical designs using both of these techniques were demonstrated. ${ }^{9}$

The approach selected to provide adequate fatigue strength during launch is the use of lighter weight materials, such as silicide coated niobium, for the skirts. The high temperature properties of rhenium are not required in the nozzle. Confidence that the material has the requisite fatigue properties was obtained during with vibration tests conducted on $67 \mathrm{~N}$ engines with a $75: 1$ area ratio rhenium nozzle. This nozzle would be significantly lighter if replaced with one made of niobium, so the tests represented a worse case. The thruster was placed in a Reaction Control Thruster Module and subjected to the acceptance level random vibration, shown in Figure 11, and successfully passed. Analysis of the strain gage and accelerometer measurements indicated that the engine design was fully capable of meeting the higher flight qualification vibration requirements, shown in Figure 11, without damage.

Rocket Test Results

Performance and life tests of practical small rocket designs using this technology were conducted. ${ }^{9}$ Both steady state and pulse testing was performed and thermal management issues were successfully addressed. A high performance $22 \mathrm{~N}$ rocket was designed to operate radiation cooled. Heat input to the forward end was managed by using an injector which delivered 30 to $40 \%$ fuel film cooling. Increased performance was obtained by tripping the fuel film layer with a patented turbulence generator to mix with the core flow. Radiative cooling was enhanced through the deposition of a high emissivity coating ( $\cong 1.0$ ) of dendritic 
rhenium on the outer surface. Temperature data versus run time depicting this thermal management is shown in Figure 12. Performance data at 150:1 area ratio for both $\mathrm{Re}$ and $\mathrm{Nb}$ engines are shown in Figure 13. A specific impulse of 310 seconds at the nominal mixture ratio of 1.65 and $690 \mathrm{kPa}$ chamber pressure using monomethylhydrazine and nitrogen tetroxide propellant is shown for this Re engine. This is about 25 seconds higher than flight qualified $22 \mathrm{~N} \mathrm{Nb}$ chamber presently in operational use. A total burn time of 1.7 hours and 100,000 cycles at a $20 \%$ duty cycle were conducted on this Re engine before it was retired. Life equivalent to that demonstrated with the Re material demonstrator chamber is projected. Tests were also conducted within a flight qualification envelope with another $22 \mathrm{~N}$ engine of the same design. These tests were conducted at mixture ratios (MR) of 1.65 and 1.90 , chamber pressures (PC) of $590 \mathrm{kPa}$ and $1100 \mathrm{kPa}$, and steady state, $10 \%$ and $70 \%$ duty cycles. The tests resulted in head end overheating at the high MR, Pc, and duty cycle test conditions. However, additional thermal design measures are expected to improve this result. No direct plume contamination measurements have been made, however, if unburned propellants are the contaminant, then the use of less fuel film coolant is certain to reduce these species in the plume.

A high performance $67 \mathrm{~N}$ engine ${ }^{9}$ was also designed, fabricated, and tested. Heat input to the forward end was managed using similar techniques as used in the 22 $\mathrm{N}$ engine. The measured specific impulse, at an area ratio of 75:1 for both $\operatorname{Re}$ and $\mathrm{Nb}$ engines is also shown in Figure 13. A specific impulse of 305 seconds is shown for the $\operatorname{Re}$ engine. This is about 20 seconds higher than the flight qualified $\mathrm{Nb}$ chamber. Projected performance for these engines at 150:1 area ratio is also shown in Figure 13. Checkout, acceptance, and some performance tests were conducted on this Re engine, enveloping some flight qualification requirements. The test range included MR from 1.4 to 1.9 , and PC from 550 to $1000 \mathrm{kPa}$. Pulse tests of $10 \%$ duty cycle only were conducted. Thirty-six (36) tests were conducted with a combined firing time of 724 seconds and a total of 339 cycles. No head end overheating was observed with the testing to date.

A $440 \mathrm{~N}$ Re engine ${ }^{5}$ was also designed and fabricated and its performance was compared to a $\mathrm{Nb}$ chamber in Figure 13. Heat input to the front end was managed using a fuel regeneratively cooled section. Performance of 308 seconds at 44:1 area ratio was achieved and the engine is projected to deliver 315 seconds at an area ratio of 150:1. This performance is about 4 seconds higher than similar $\mathrm{Nb}$ engines. A higher area ratio of $467: 1$ is projected to deliver 321 seconds, as shown in Figure 13. Performance test results $s^{5}$, using an injector from a prior program ${ }^{10}$, indicate that higher performance is achievable. Performance of 314 seconds at an area ratio of 44:1 was measured. This performance is about 10 seconds higher than the $\mathrm{Nb}$ engine. Tests are underway to envelope flight qualification requirements with this engine, as well as an acceptance level vibration test.

Some quantification of benefits due to the use of Ir-Re engine technology is discussed in Reference 9 . Benefits, however, are very application sensitive. It is generally conceded that the lifes of communication satellites are limited by propellant supply and that many NASA and DOD missions are performed driven.

\section{Summary}

A development program is underway to provide the requisite material characterizations and fabrication technologies to incorporate iridium coated 
rhenium material into small rockets for spacecraft propulsion. Material demonstrator rocket chambers successfully completed 17 hours of 1 ife at operating temperatures of $2200^{\circ} \mathrm{C}$, along with 100,000 cycles using MMH/NTO propellants. Design, fabrication, and testing of rocket chambers in several thrust classes have demonstrated thermal management of the head end of the rocket, along with up to 25 seconds higher specific impulse than similar flight qualified designs in operational use today. Tests to envelope flight qualification requirements have been conducted and are being pursued as a continuing effort.

\section{References}

1. Stechman, R., "Development History of the $251 \mathrm{bf}$ (110 Newton) Space Shuttle Vernier Thruster," AIAA Paper 90-1837, 26th Joint Propulsion Conference, Orlando, Florida, July 1990.

2. Stechman, R. and Sumpter, D., "Development History of the Apollo Reaction Control System Rocket Engine," AIAA Paper 89-2388, 25th Joint Propulsion Conference, Monterey, CA, July 1989.

3. Gilroy, R. and Sackheim, R., "The Lunar Module Descent Engine - A Historical Summary," AIAA Paper 89-2385, 25th Joint Propulsion Conference, Monterey, CA, July 1989.

4. Wooten, J.R. and Lansaw, P.T., "High-Temperature 0xidation-Resistant Thruster Research," NASA-CR-185233, February 1990.

5. Advanced Small Rocket Chambers, NASA Contract NAS3-25646, Final Report to be published.

6. Krohn, D. D., "Space Shuttle Vernier Thruster Long-Life Chamber Development," AIAA Paper 90-2744, 26th Joint Propulsion Conference, Orlando, FL, July 1990.

7. Harding, J.T., Kazaroff, J. M., and Appe1, M. A., "Iridium-Coated Rhenium Thrusters by CVD," Proceedings of the Second International Conference on Surface Modification Technologies, Chicago, IL, September 1988.

8. Hamilton, J. C., Yang, N. Y. C., Clift, W. M., Boehme, D. R., McCarty, K. F., and Franklin, J., "Diffusion Mechanisms in Iridium-Coated Rhenium for High-Temperature, Radiation-Cooled Rocket Thrusters, " AIAA Paper 91-2215, 27th Joint Propulsion Conference, Sacramento, CA, June 1991.

9. Rosenberg S. D. and Schoenman, L., "High Performance Bipropellant Engines for Orbit Transfer and Attitude Control Propulsion," IAF Paper 91-249, 42nd Congress of the International Astronautical Federation, Montreal, Canada, October 1991.

10. Schoenman, L., Franklin, J., and Lansaw, P. T., "Feasibility Demonstration of a High-Performance 100 1bf Rocket Engine," JPL Contract 957882 Final Report, January 1989. 


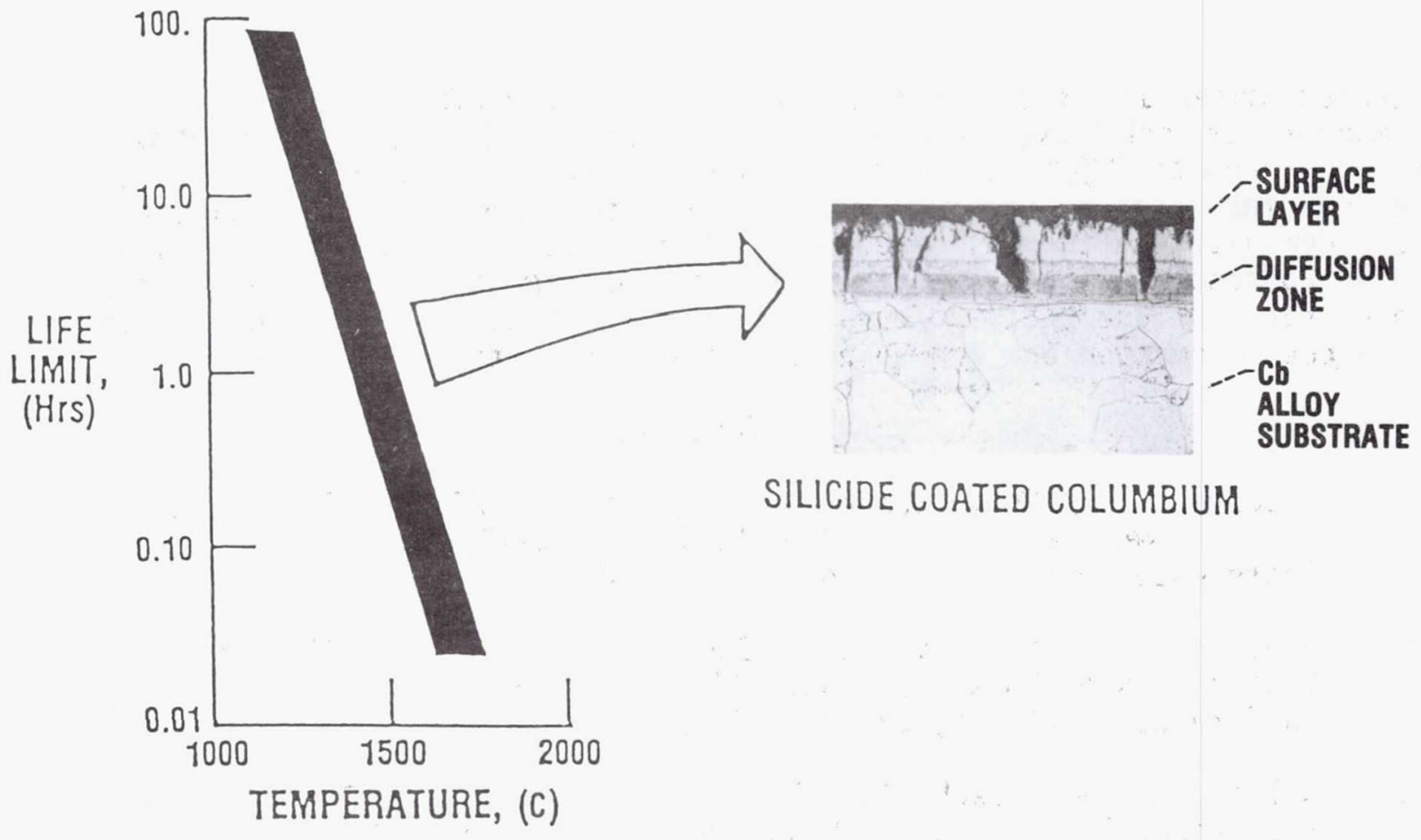

Figure 1. Life vs. operating temperature for state-of-art Earth storable bipropellant rockets. (Reference 6.)

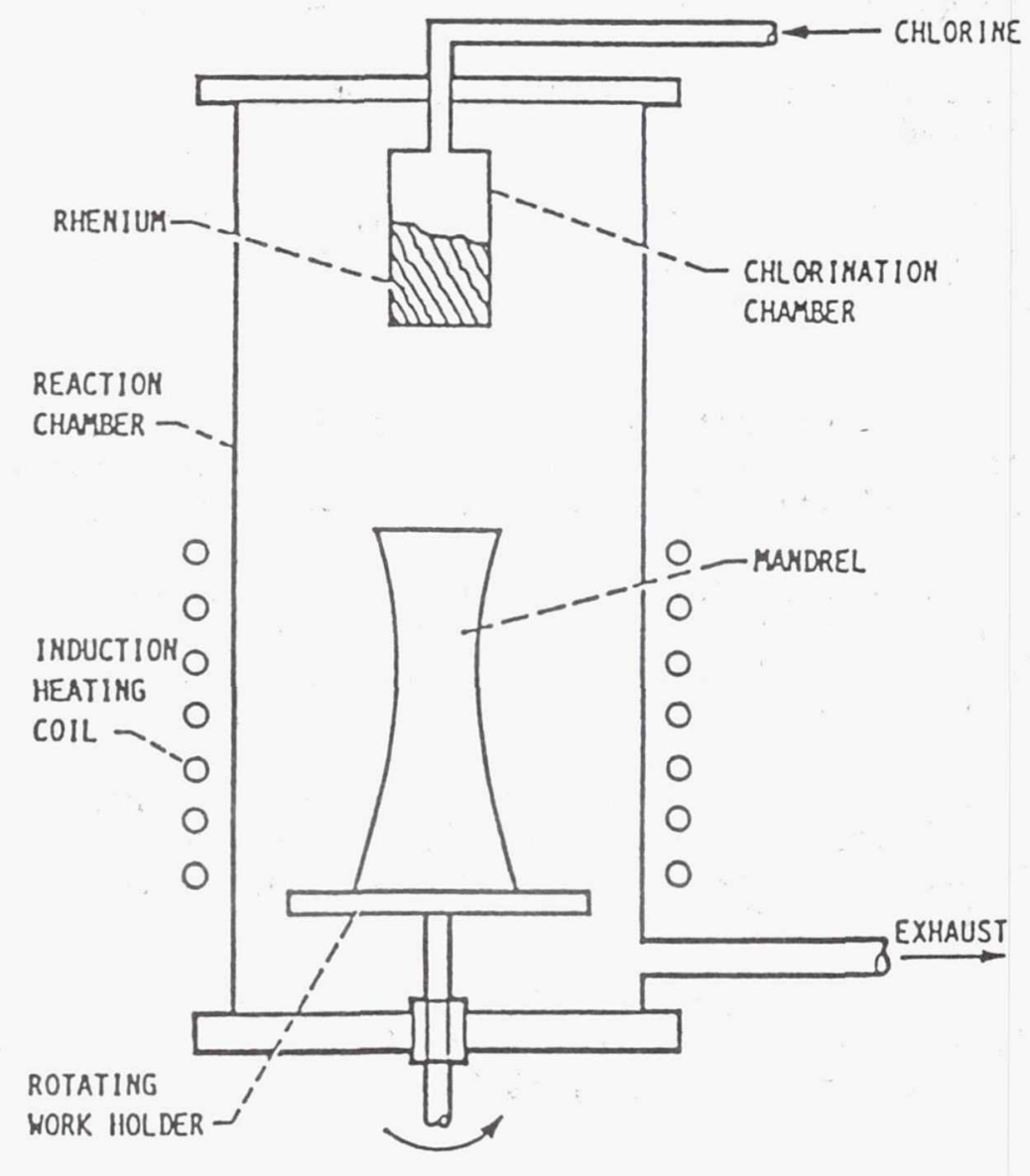

Figure 2. Schematic of CVD apparatus for rhenium deposition. (Reference 7.) 


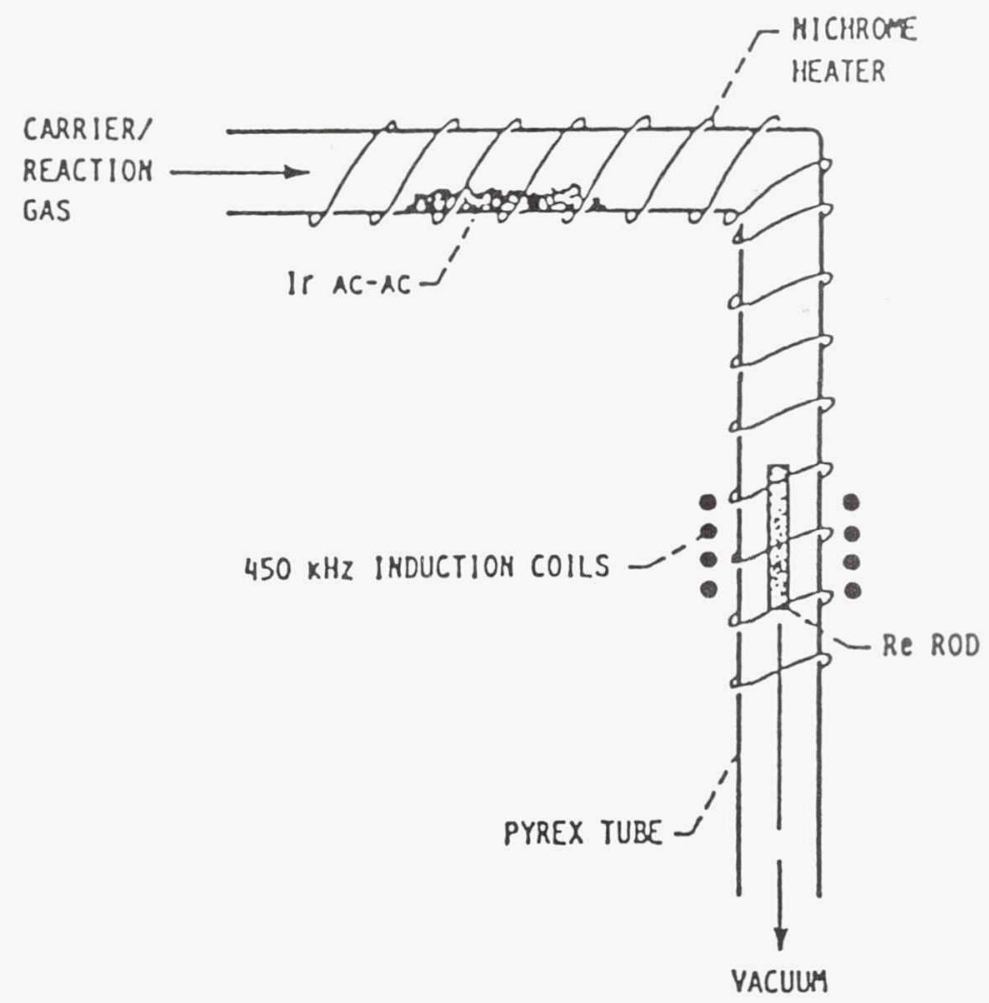

Figure 3. Schematic of CVD apparatus for iridium deposition. (Reference 7.)

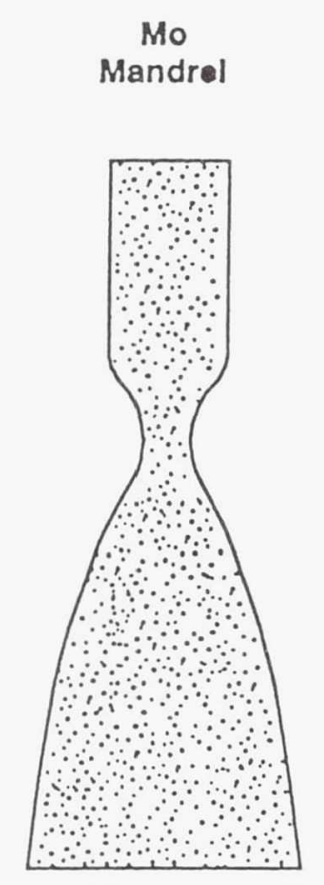

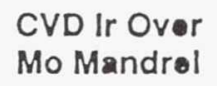

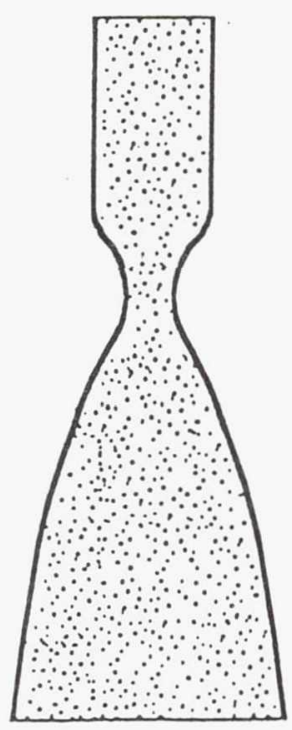

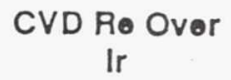

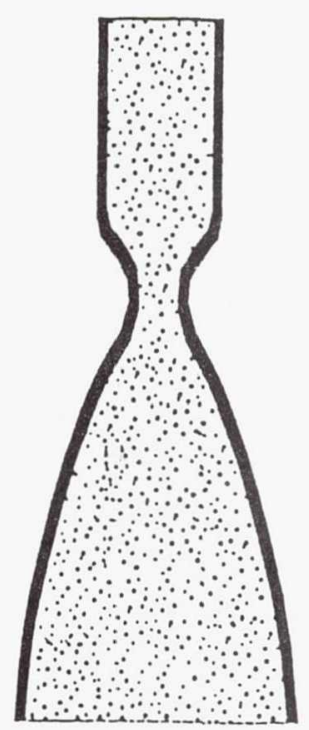

Remove

Mo Mandrel

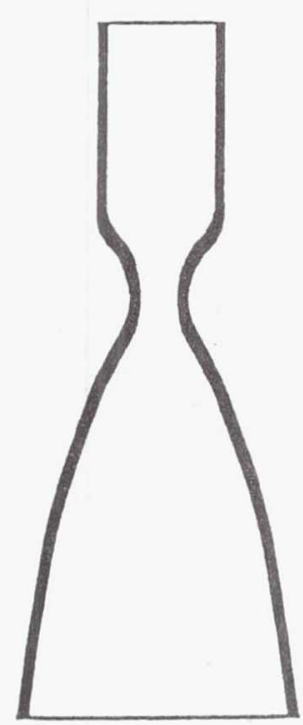

Figure 4. Schematic of fabrication process used for CVD iridium-rhenium thrusters. 


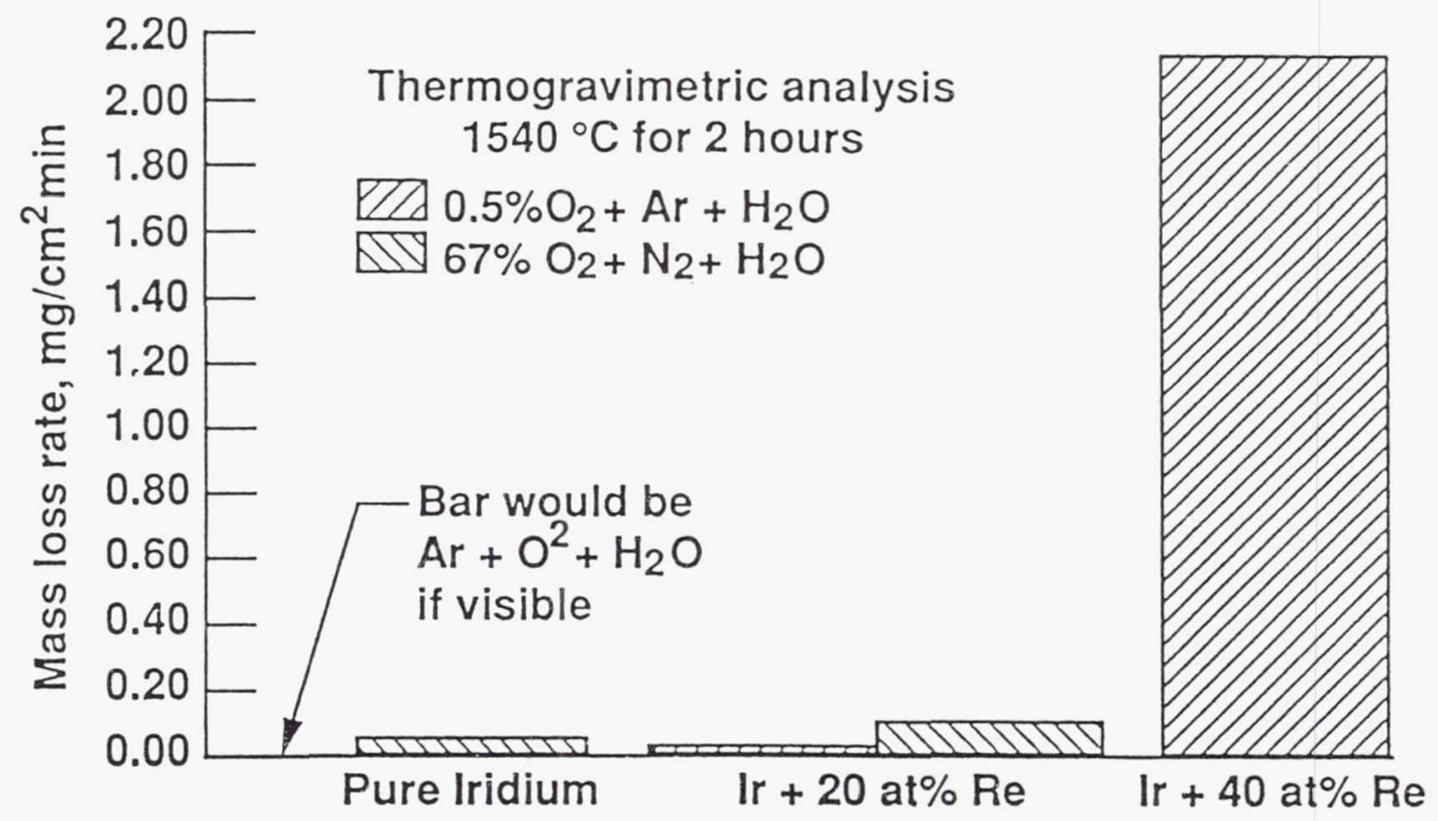

Figure 5. Oxidation rates of iridium and iridium-rhenium alloys. (Reference 4.)

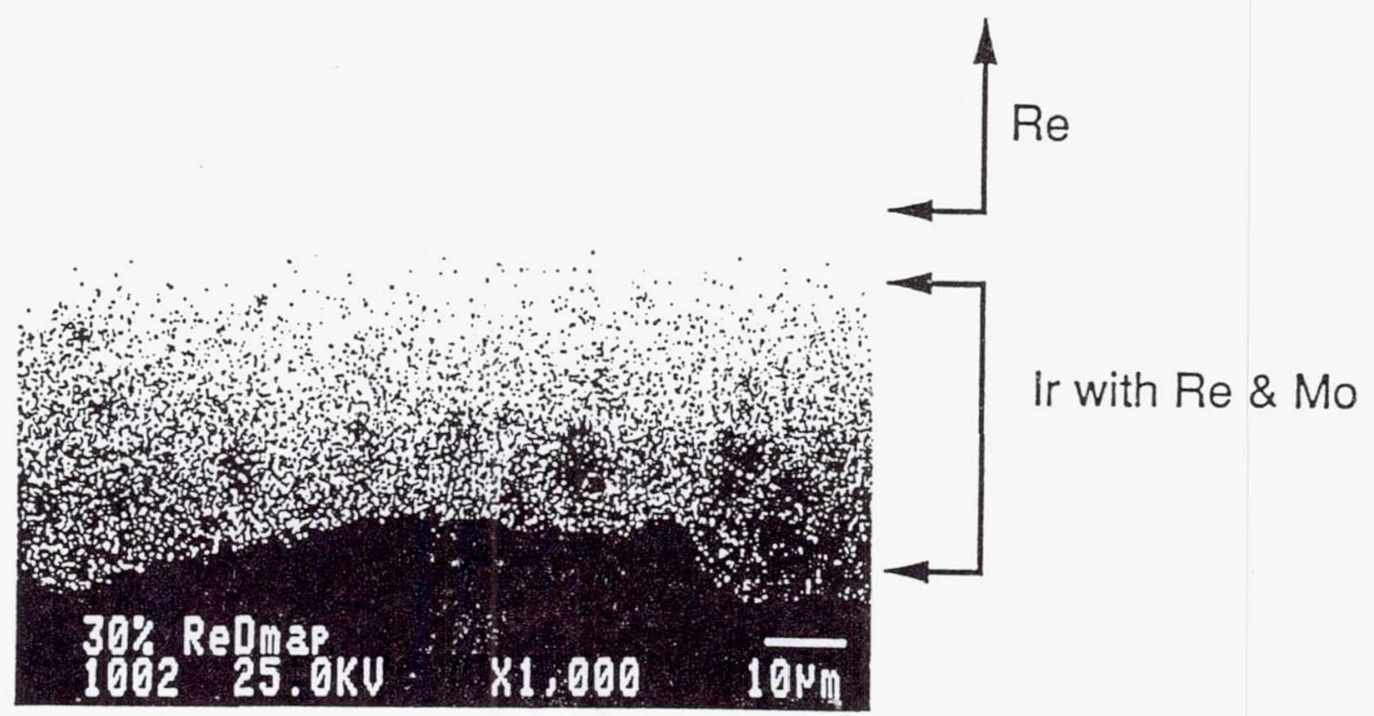

Figure 6. Electron microprobe analysis of cross section of iridium-rhenium specimen vacuum anealed at $1900^{\circ} \mathrm{C}$ for 8 hours. (Reference 8.) 


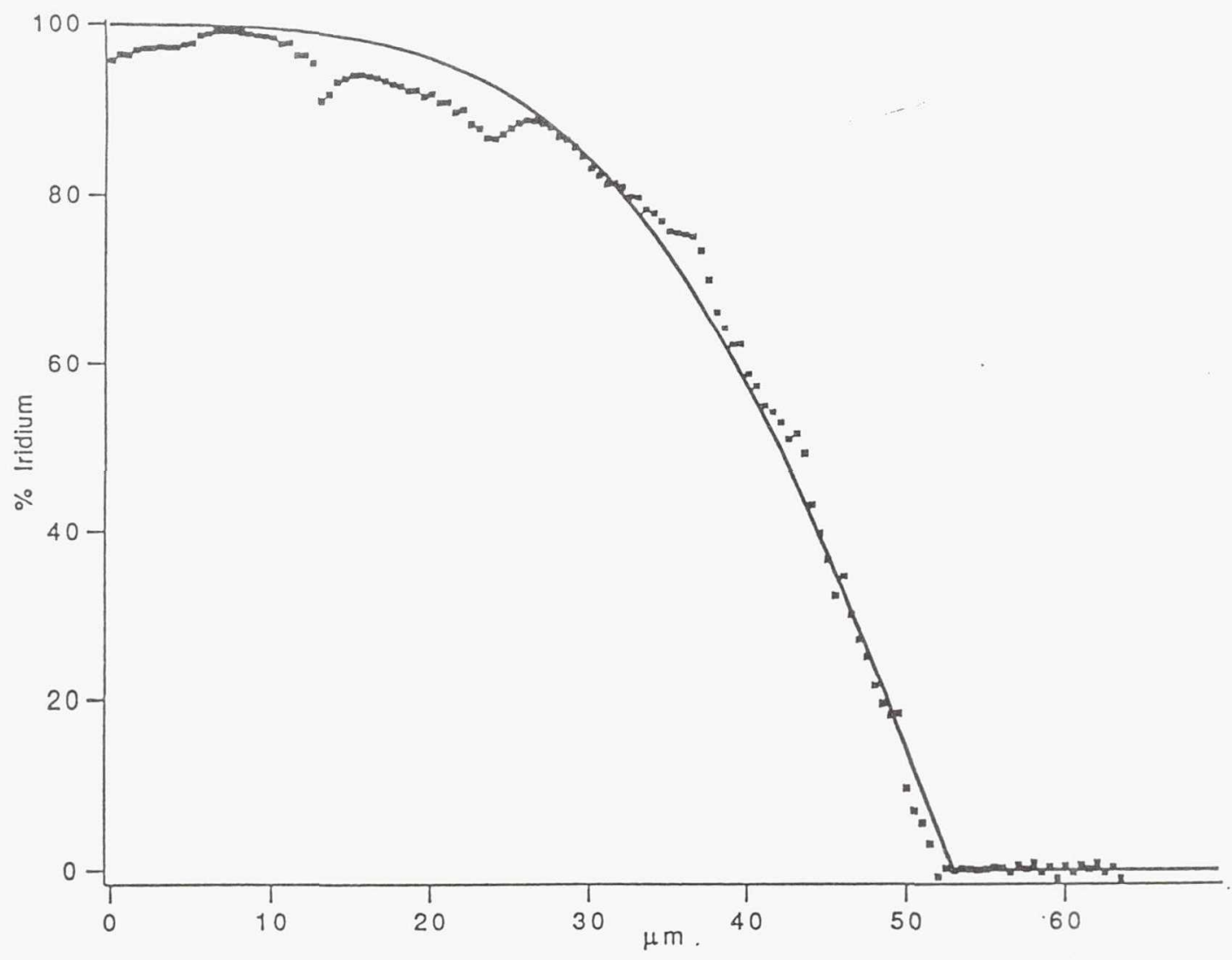

Figure 7. Iridium profile through an iridium-rhenium specimen vacuum anealed at $1900{ }^{\circ} \mathrm{C}$ for 8 hours. (Reference 8 .)

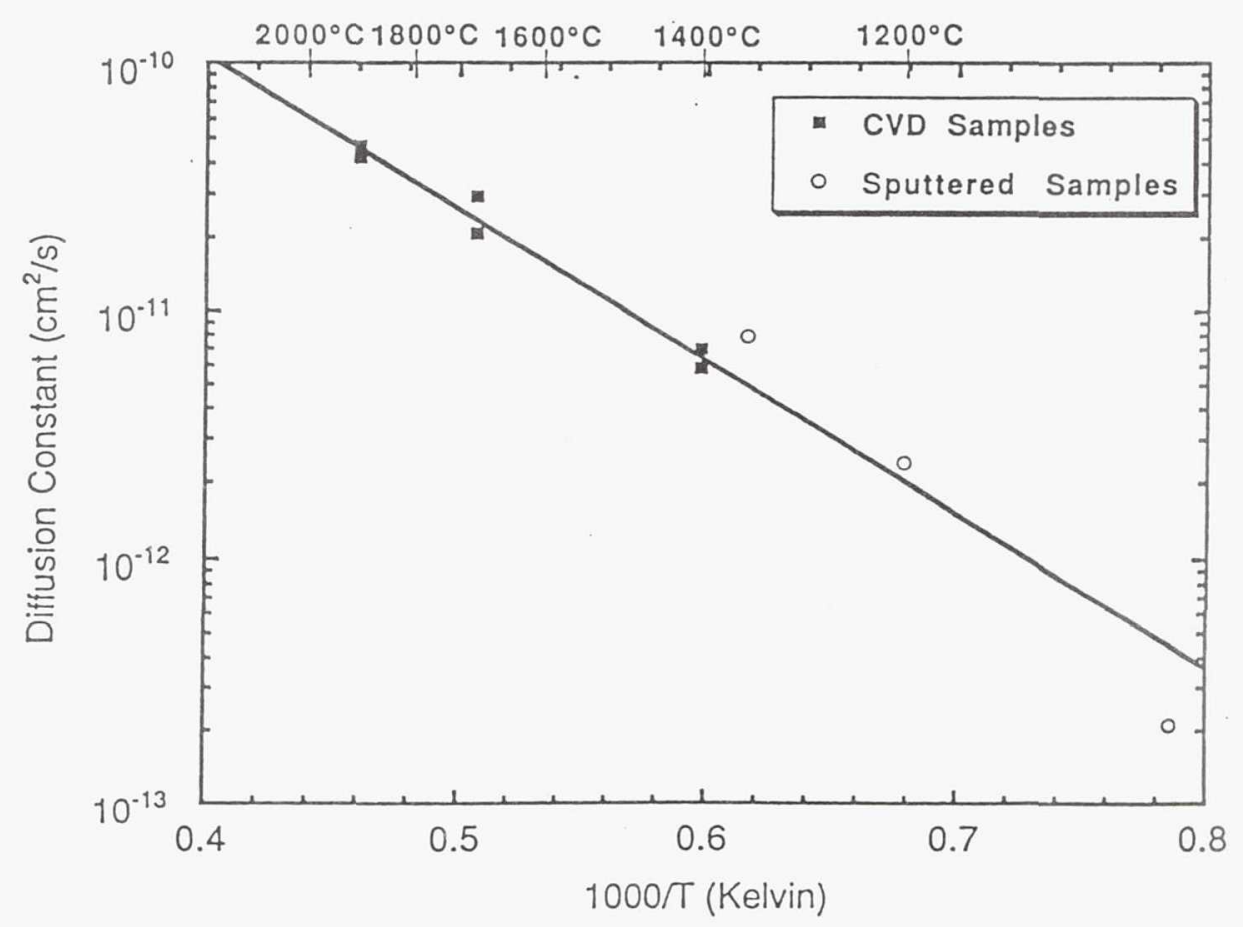

Figure 8. Measured diffusion constants of iridium-rhenium couples showing Arrhenius dependence. (Reference 8.) 


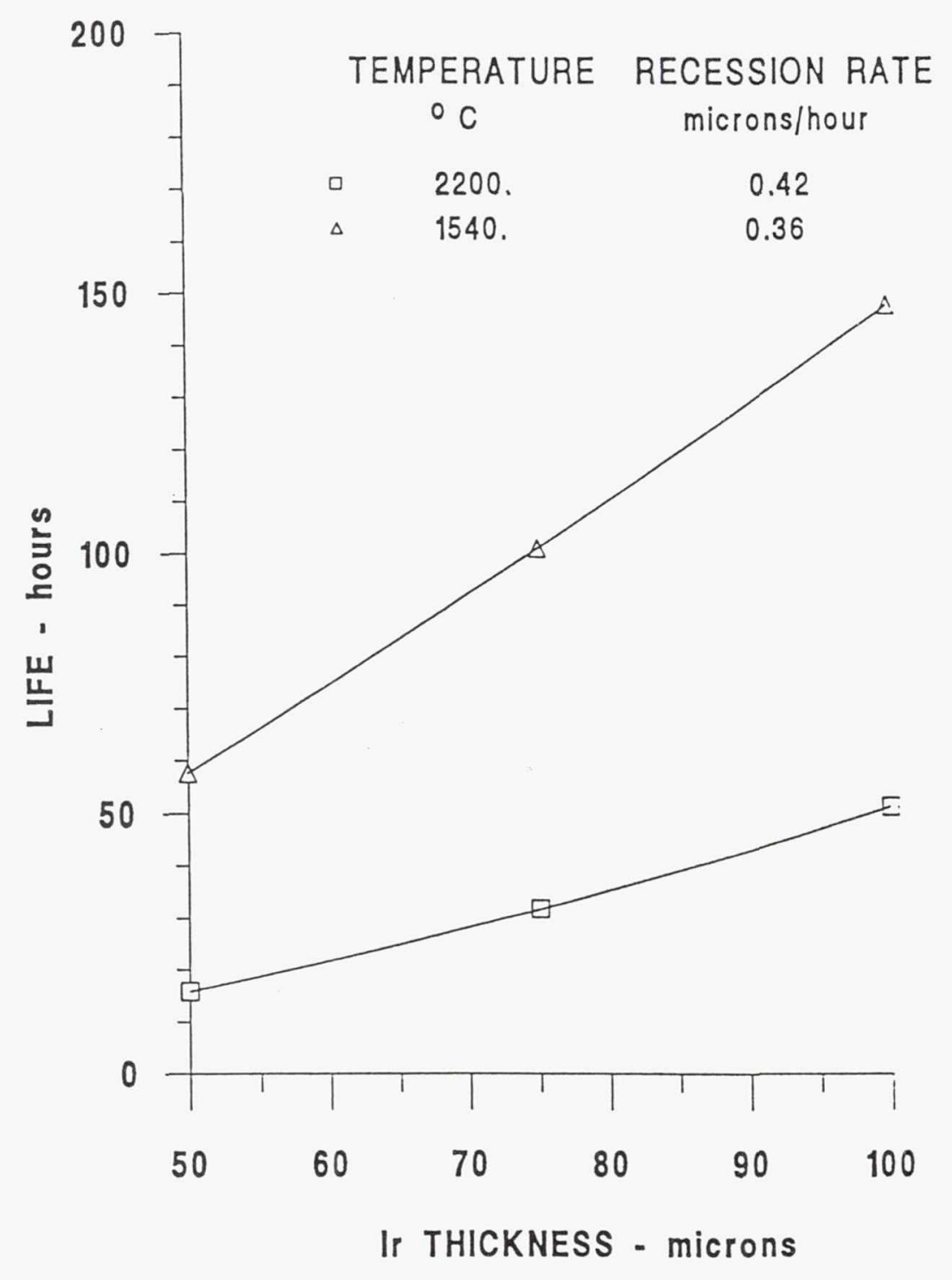

Figure 9. Life prediction model for iridium coated rhenium thrusters. 
Fracture Shear Stress $(\mathrm{kPa})$

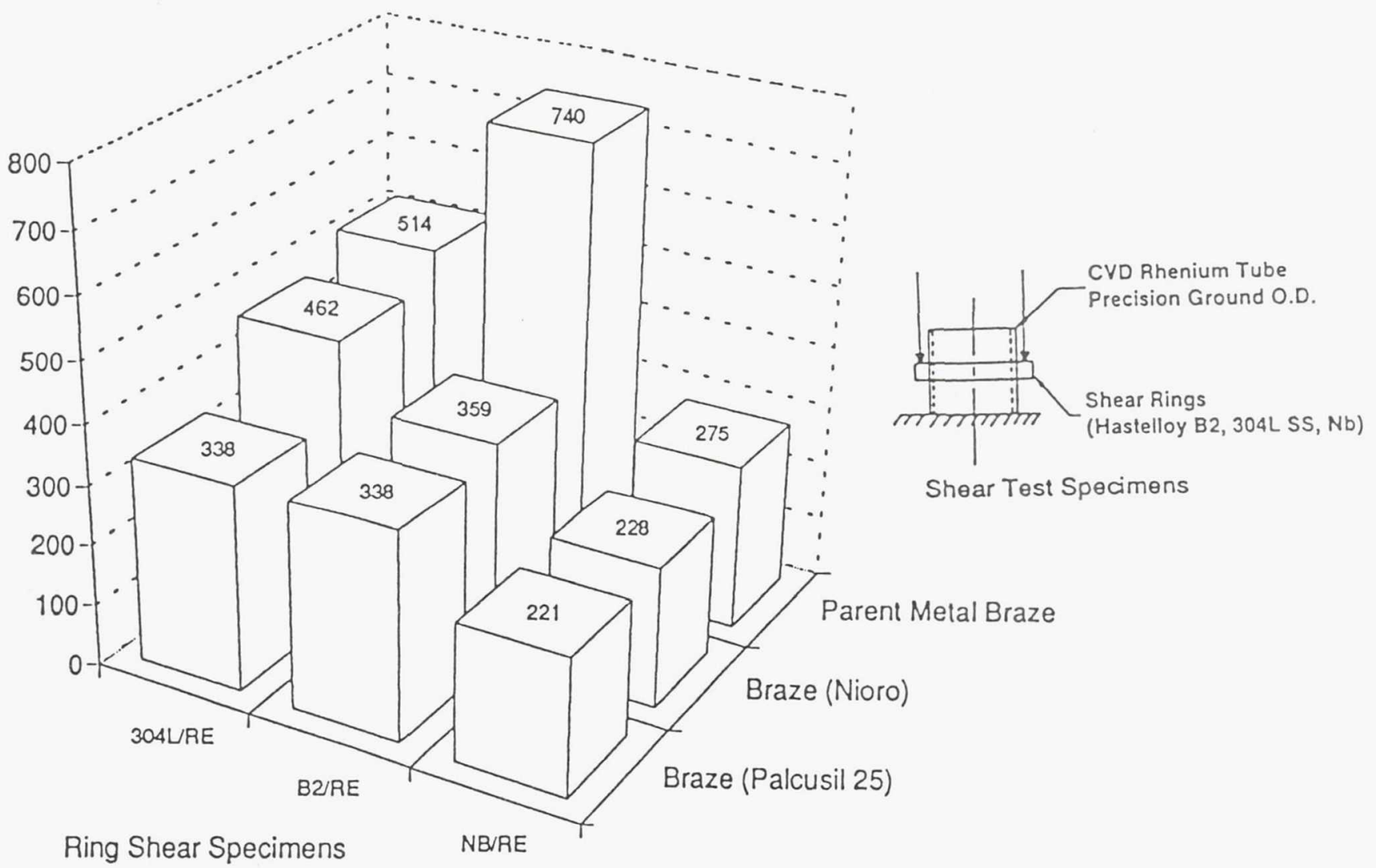

Figure 10. Fracture shear stress of dissimilar metal joints with rhenium using several joining techniques. (Reference 4.)

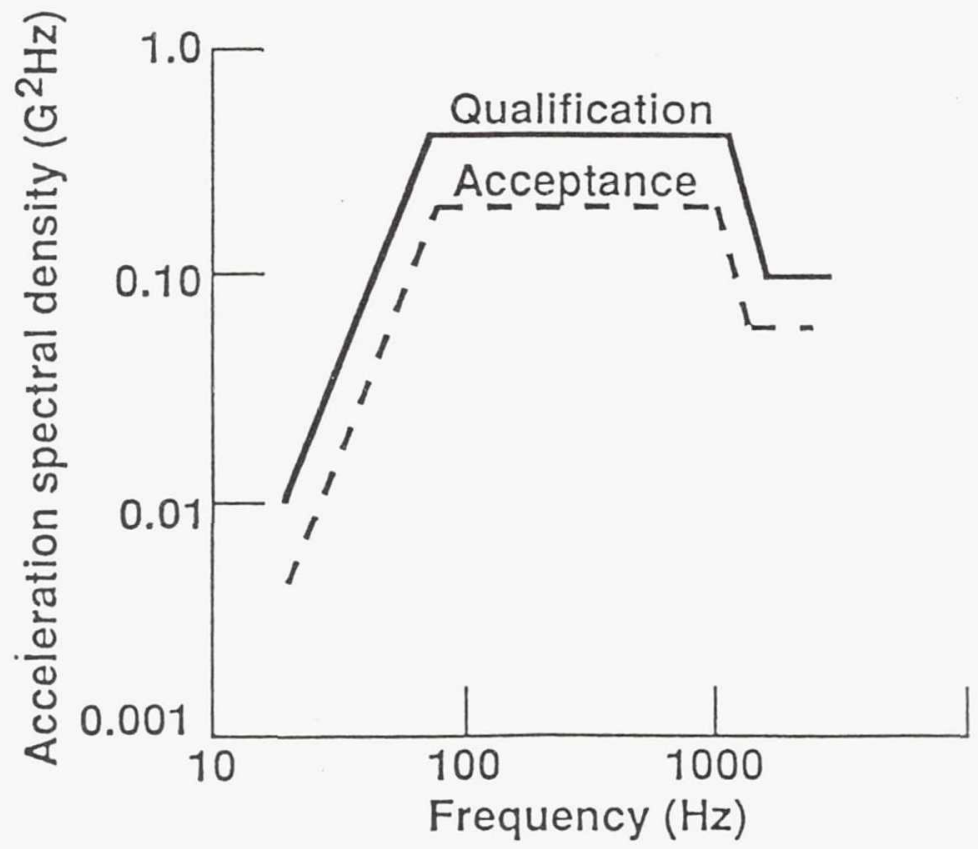

Figure 11. Random vibration specifications for testing reaction control thruster modules. (Reference 5.) 


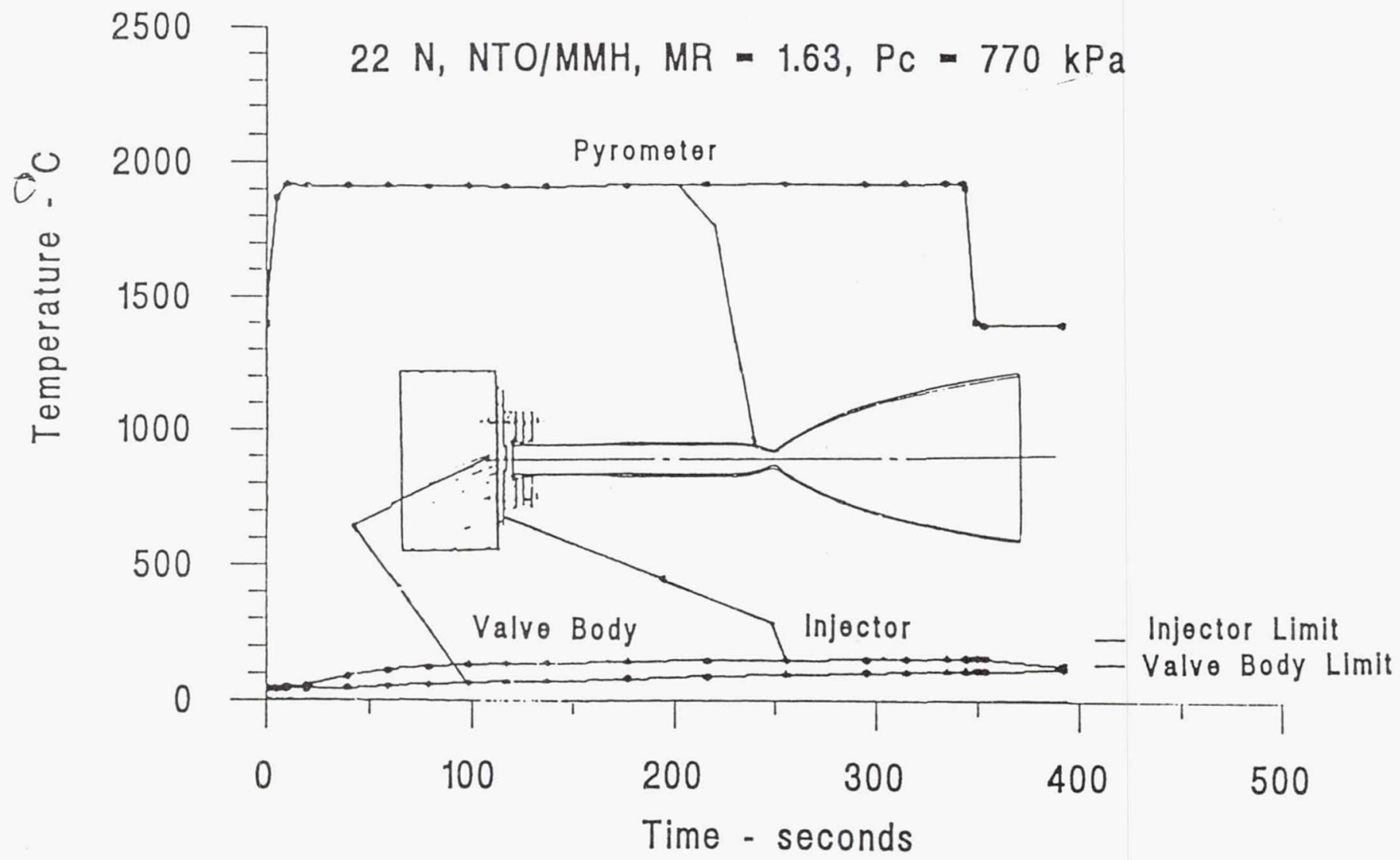

Figure 12. Temperature vs. time history showing forward end thermal management. (Reference 4.)

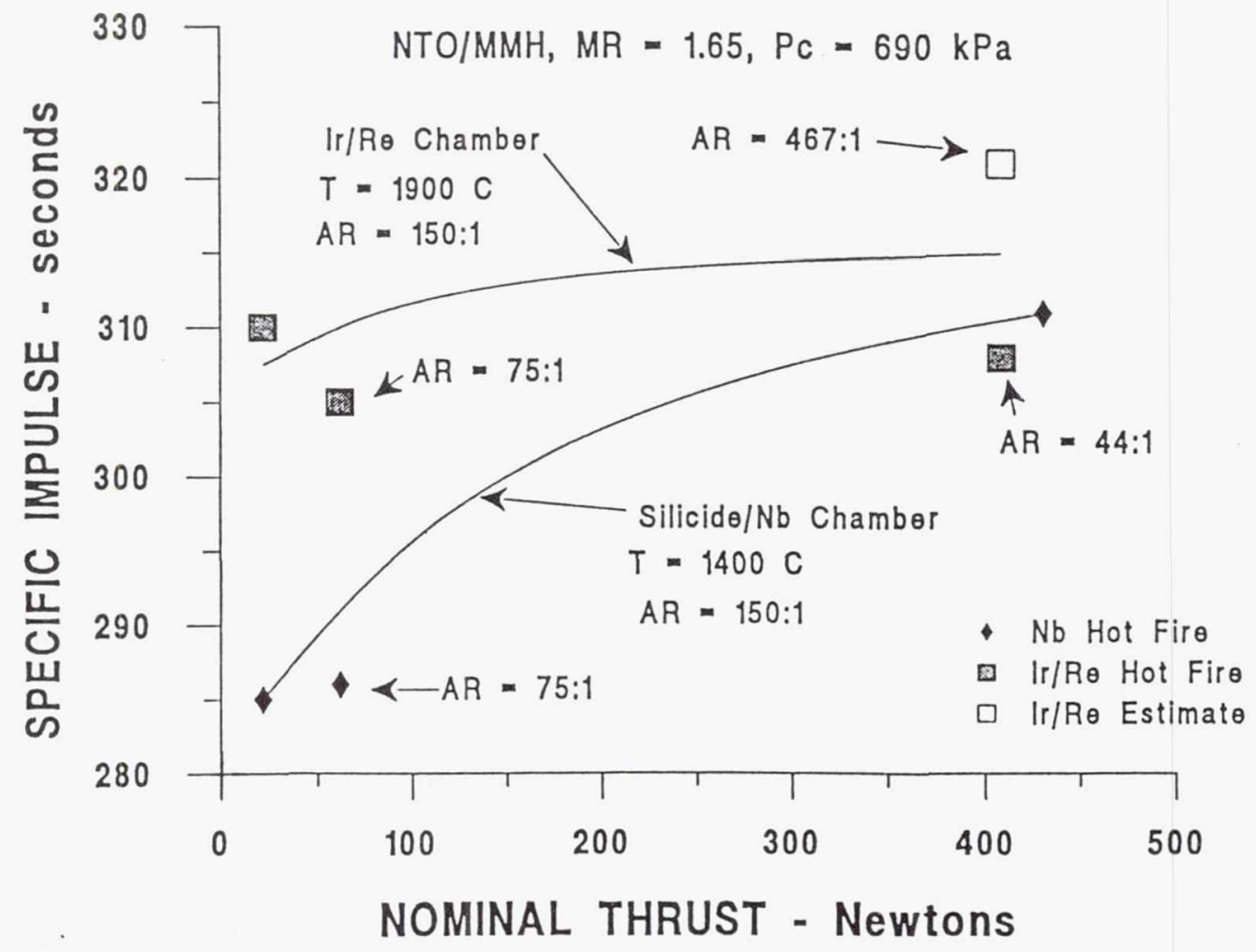

Figure 13. Performance comparison of Re and Nb chambers. 


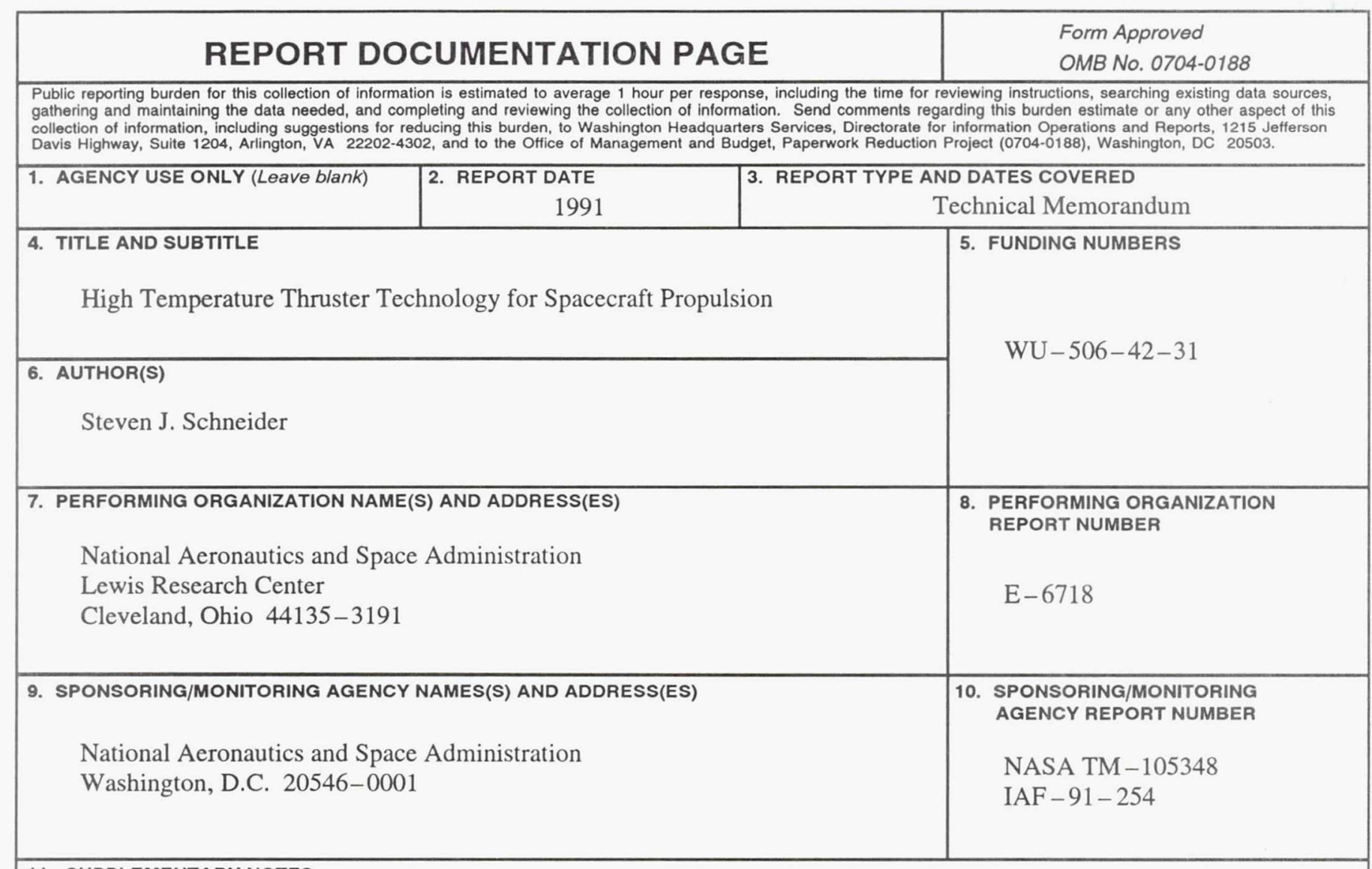

11. SUPPLEMENTARY NOTES

Prepared for the 42nd Congress of the International Astronautical Federation, Montreal, Canada, October 5-11, 1991.

Responsible person, Steven J. Schneider, (216) 977-7484.

12a. DISTRIBUTION/AVAILABILITY STATEMENT

12b. DISTRIBUTION CODE

Unclassified - Unlimited

Subject Category 20

13. ABSTRACT (Maximum 200 words)

A technology program has been underway since 1985 to develop high temperature oxidation-resistant thrusters for spacecraft applications. The successful development of this technology will provide the basis for the design of higher performance satellite engines with reduced plume contamination. Alternatively, this technology program will provide a material with high thermal margin to operate at conventional temperatures and provide increased life for refuelable or reusable spacecraft. The new chamber material consists of a rhenium substrate coated with iridium for oxidation protection. This material increases the operating temperature of thrusters to $2200^{\circ} \mathrm{C}$, a significant increase over the $1400^{\circ} \mathrm{C}$ of the silicide-coated niobium chambers currently used. Stationkeeping class $22 \mathrm{~N}$ engines fabricated from iridium-coated rhenium have demonstrated steady state specific impulses 20 to 25 seconds higher than niobium chambers. Ir-Re apogee class $440 \mathrm{~N}$ engines are expected to deliver an additional 10 to 15 seconds. These improved performances are obtained by reducing or eliminating the fuel film cooling requirements in the combustion chamber while operating at the same overall mixture ratio as conventional engines. The program is attempting to envelope flight qualification requirements to reduce the potential risks and costs of flight qualification programs.

14. SUBJECT TERMS

Rockets; Satellite propulsion; Rhenium thrusters; Iridium coatings; Chemical vapor deposition; Bipropellants; Radiation cooling; High-performance; Long life; High temperature

17. SECURITY CLASSIFICATION OF REPORT Unclassified

18. SECURITY CLASSIFICATION
OF THIS PAGE
Unclassified

19. SECURITY CLASSIFICATION OF ABSTRACT Unclassified
15. NUMBER OF PAGES 16

16. PRICE CODE $\mathrm{AO3}$

20. LIMITATION OF ABSTRACT 